\title{
LETTER
}

\section{Evaluation of a commercial infant body plethysmograph}

\section{To the Editor:}

E. Jaeger GmbH \& Co. KG (Würzburg, Germany) was one of the pioneers who manufactured a commercialized body plethysmograph for infants. Recently, a new version of this commercial device was presented. The company accepted the offer of two technical university institutes and a university paediatric department to co-operate in the evaluation of their infant body plethysmograph. The findings were compared with recommendations of the European Respiratory Society and the American Thoracic Society $[1,2]$.

The Jaeger infant whole-body plethysmograph is a constant volume/variable pressure plethysmograph. A detailed description of the apparatus is available in the original manual [3]. A brief profile of the selected parts assessed in this study is specified here. The chamber is constructed of a removable, ark-shaped, transparent acrylic plastic cover, based on the wooden ceiling of a cart. The joint between the floor and cover is sealed with a rubber tape and magnetic locks. A small round opening in the cover (port) enables the operator to put his or her forearm into the chamber to control the position of the face mask during lung function tests (LFT). The leak between the opening and the arm is sealed by a neoprene cuff. Pressure changes within the plethysmograph are measured by a Jaeger builtin differential pressure transducer that is connected to the chamber by stiff polyvinyl chloride (PVC) tubes. Slow pressure increases within the body box due to the patient's heat emission during LFT are compensated for by air leakage. A body temperature, ambient pressure and water saturation (BTPS) unit made of transparent acrylic plastic $(2500 \mathrm{~mL}$ volume) was introduced by the manufacturer for measurements of airways resistance (Raw). BTPS conditions in the unit are accomplished as follows. Air driven by a heated blower passes a humidifier and circulates within the BTPS unit. Humidity is assumed to be sufficient if water is condensing on the walls of the inspiratory tube. Temperature is controlled by a thermostat. During LFT, the unit is opened to the pneumotachograph. Pressure changes inside the unit are equalized with that of the body chamber by a tube (50 $\mathrm{cm}$ length and $180 \mathrm{~mL}$ volume) connected to the expiratory line of the BTPS unit.

An assessment was made of the time constant, the frequency response of the plethysmograph and the dead space of the pneumotachograph. During the evaluation all joints of the chamber and the manipulation port were carefully sealed. The signals from the chamber pressure transducer were recorded after analogue filtering and amplification prior to digitization. BTPS conditions, accumulation of carbon dioxide $\left(\mathrm{CO}_{2}\right)$, partial pressures of carbon dioxide $\left(\mathrm{PCO}_{2}\right)$ and oxygen $\left(\mathrm{PO}_{2}\right)$ and oxygen saturation $\left(\mathrm{SO}_{2}\right)$ were monitored transcutaneously during lung function measurements in six infants.
To measure the total time constant, different amounts of air $(2,5$ and $10 \mathrm{~mL})$ were injected into the chamber, using an appropriate syringe, after thermal equilibration. The first tests were performed with the port sealed and were repeated six times on two different days. Another series of tests was conducted with an operator putting his forearm into the chamber through the port, as during LFT. The time constant for each test was calculated from the time taken for the pressure to fall to $37 \%$ of its initial value. The frequency response was investigated by sinus wave pressure fluctuations. In brief, pressure waves were generated by a $40 \mathrm{~mL}$ volume loudspeaker connected to the body chamber and the volume displacement was measured. Analogue signals were digitized and analysed by a frequency analyser (FFT analyzer CF-360; Ono-Sokki, Tokyo, Japan). The amplitude ratio and phase shift between input (loudspeaker) and output (Jaeger transducer) were calculated for the frequency range $0-20 \mathrm{~Hz}[2,4]$. To assess BTPS conditions, humidity and temperature were measured near the face mask and inside the BTPS unit. Near the face mask, a self-constructed $\mathrm{NiCr} / \mathrm{Ni}$ thermocouple (wire diameter 0.5 $\mathrm{mm}$ ) followed the fast temperature fluctuations during the breathing cycle of infants. The thermal voltage generated by the thermocouple was amplified by integrated circuits (AD 595 AQ; Analog Devices, IC, Norwood, USA). The un-certainty caused by amplification was $<1.5 \%$. A Pt- 100 temperature probe was placed within the BTPS unit. Signals were amplified by an amplifier with a maximal nonlinearity of less than $0.03 \%$ (INA101; Burr-Brown, Tucson, USA). Both types of thermal sensors were calibrated in water with exactly controlled temperatures at 0 and $50^{\circ} \mathrm{C}$. Humidity near the patient's mouth was determined by a self-constructed probe based on a small, fast response sensor element (H5000; Coreci, Lyon, France). Humidity within the rebreathing unit was recorded by a commercial probe (IH-3602-L; HY-Cal Engineering, El Monte, USA; linear response between 0 and 100\%). Both humidity sensors were calibrated in the atmosphere above saturated salt solutions of $\mathrm{NaCl}$ or $\mathrm{KNO}_{4}$ at 76 and $93 \%$ relative hu-midity, respectively. The signal from the self-constructed sensor was found to be linear in this humidity range. The analogue changes in signals from both the thermocouples and from the relative humidity probes were converted by a 12-bit ADC-board (MIO-16L9; National Instruments, Austin, USA) and recorded to a personal computer. Using an interface developed under the graphical programming language LabVIEW® (National Instruments) the data acquisition rate amounted to three points per second. The carbon dioxide level and patient's blood gases were examined during LFT in six former preterm infants (age 3-14 months) while a clinical routine LFT procedure was performed. $\mathrm{SO}_{2}, \mathrm{PO}_{2}$ and $\mathrm{PCO}_{2}$ were monitored by transcutaneous probes (Oxyshuttle ${ }^{\circledR}$ and Transent II®; SensorMedics, Anaheim, USA). $\mathrm{PCO}_{2}$ was monitored inside the rebreathing 
unit by means of an infrared absorption spectrometer (Oscar®, Datex-Engström, Bremen, Germany). Values were collected once per minute. The LFT was interrupted if $\mathrm{SO}_{2}$ fell by $>5 \%$ or $<90 \%$.

The results are summarized in table 1 . While a plethysmograph with a chamber volume of $85 \mathrm{~L}$ provides the opportunity to study LFT in infants up to $12 \mathrm{~kg}$ it may not meet the sensitivity requirements of very small neonates. During Raw measurements, changes in chamber volume may be smaller than $1 \mathrm{~mL}$, or translated to a pressure of $<0.12 \mathrm{cmH}_{2} \mathrm{O}$ [2]. A larger than recommended dead space was found in the pneumotachograph. This may lead to rebreathing, especially in very small neonates. The time constant did not reach the recommended range, even with the sealed port. With the forearm of an investigator in the chamber, the time constant was shortened significantly and varied with the air volume injected. A sufficient total time constant permits the elimination of unwanted pressure drifts without attenuating signal size at the lowest breathing frequencies observed [2,5]. It is helpful to be able to correct the face mask position and to support the cheeks during the test. However, the potential advantages are obviously counterbalanced by the disadvantage of leakage between the neoprene seal and the operator's forearm. An adjustable rod supports the face mask inside other infant plethysmographs [2,4]. A similar device is now of-fered by Jaeger. The frequency response of the Jaeger plethysmograph did not meet the recommended values $[2,6]$. Depressed amplitude and large phase shift may stem from the leakage, the self-constructed pressure transducer, and/or the length and width of the connecting tubes. Further examination is necessary to discriminate between the different possibilities.

Proper body temperature and saturation conditions were not always provided by the rebreathing system. Before connecting infants to the BTPS unit considerable deviations from BTPS conditions were found. After connecting the infant to the rebreathing unit the temperature gradually approached $37^{\circ} \mathrm{C}$ but was still fluctuating at the face mask. Relative humidity did not reach the expected value $>95 \%$

Table 1. - Technical results and patient-related data

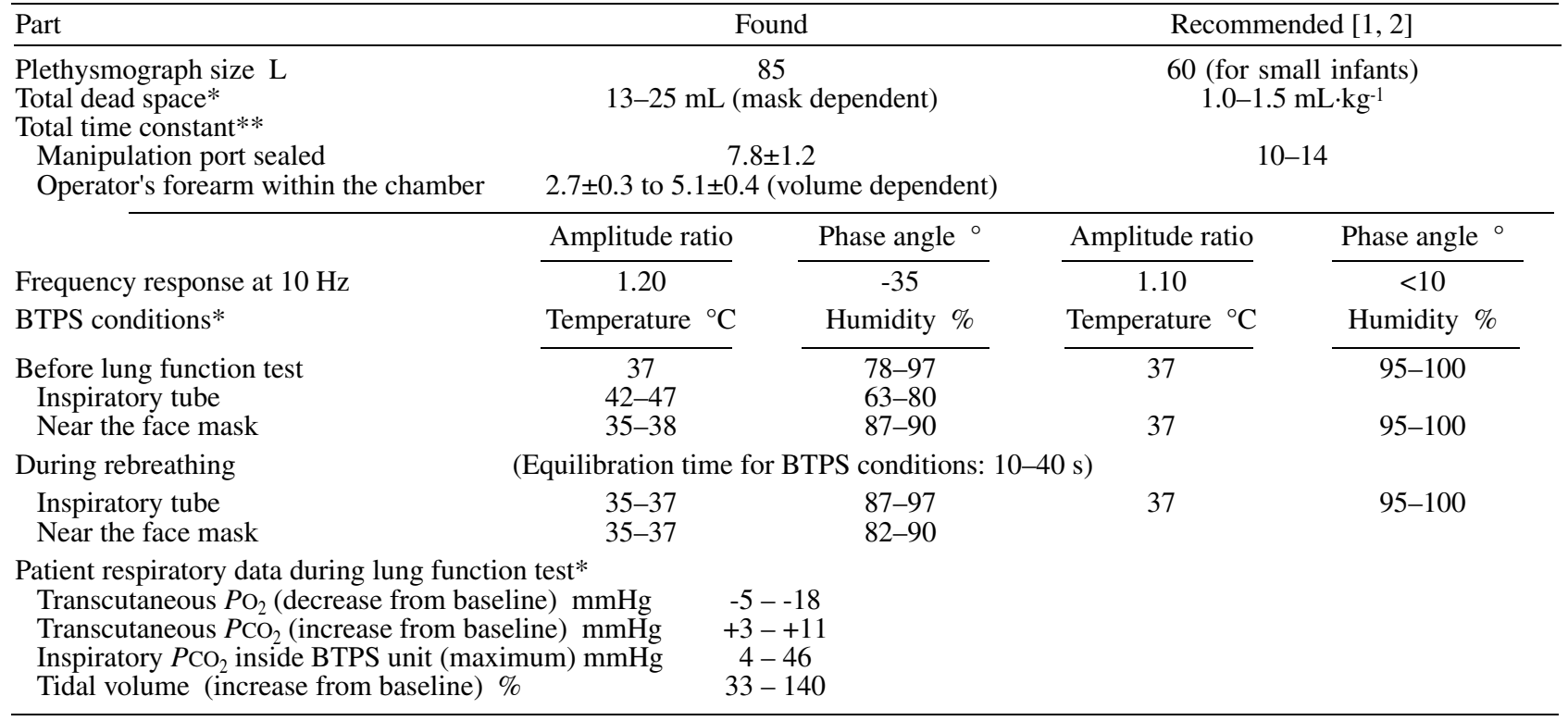

and open flow-pressure loops during LFT were exhibited in the older infants. While the relatively dry and very hot air introduced to the infant may be harmless, it may also induce bronchospasm in hyperreactive airways by drying out the bronchial mucus. The possible volume error related to the observed maximal deviation from BTPS conditions was calculated [7] $\left(35^{\circ} \mathrm{C}, 87 \%\right.$ relative humidity during steady state). The maximum volume expansion caused by the temperature increase amounted to $0.7 \%$ of tidal volume (VT) and that related to the humidity deviation amounted to $4.5 \%$ VT. Both VT errors could expand during inspiration by about $5.2 \%$. Moreover, during $R$ aw measurements the error may rise to about $50 \%$ of the pressure signal, since the pressure signal of the body chamber recorded during the measurements is equivalent to a volume displacement of less than $10 \%$ of VT [2].

During the Raw measurements, $\mathrm{PCO}_{2}$ within the BTPS unit increased significantly. In the largest infant $(9 \mathrm{~kg})$ $\mathrm{PCO}_{2}$ values exceeded the normal end expiratory range. The hypercapnia was accompanied by a rise in VT. Both may alter lung function parameters $[2,8]$. The $2500 \mathrm{~mL}$ of the Jaeger BTPS unit allows longer rebreathing periods without removing the face mask, but this advantage is offset by the longer time needed to reach steady-state conditions, by which time considerable quantities of $\mathrm{CO}_{2}$ have accumulated. The attempt to prevent $\mathrm{CO}_{2}$ accumulation by air exchange between the BTPS unit and the body chamber via a tube was not successful. A concurrent decrease in $\mathrm{PO}_{2}$ was observed in all patients; however, owing to the sigmoidal relationship between $\mathrm{PO}_{2}$ and $\mathrm{SO}_{2}$, oxygenation remained in a tolerable range with $\mathrm{SO}_{2}>90 \%$.

We are thankful to E. Jaeger $\mathrm{GmbH} \& \mathrm{Co}$. KG, who agreed with an independent scientific assessment of the product. Consequently, several modifications should be in the interest of and of benefit to all concerned with infant lung function tests. The results of this study confirm the opinion that it is not sufficient to rely on the carefulness of manufacturers and their specifications, but to have the equipment assessed by independent clinicians and engineers.

\footnotetext{
$*$ : range; $* *$ : mean \pm SD.
} 


\section{References}

1. ATS-ERS Statement: Respiratory mechanics in infants: Physiologic evaluation in health and disease. Eur Respir J 1993; 6: 279-310.

2. Stocks J, Sly PD, Tepper RS, Morgan WJ, eds. Infant respiratory function testing. New York, Wiley-Liss, 1996.

3. E. Jaeger GmbH \& Co. KG. BabyBody Handbuch, Teil 1, Würzburg, 1993.

4. Stocks J, Levy NM, Godfrey S. A new apparatus for the accurate measurement of airway resistance in infancy. $J$ Appl Physiol: Respir Environ Exercise Physiol 1977; 43: 155-159.

5. Coates AL, Peslin R, Rodenstein D, Stocks J. Measurement of lung volumes by plethysmography. Eur Respir $J$ 1997; 10: 1415-1427.

6. Stocks J, Beardsmore C, Helms P. Infant lung function:
Measurement conditions and equipment. Eur Respir $J$ 1989; 2: Suppl. 4, 123s-129s.

7. Dobrinski P, Krakau G, Vogel A. Physik für Ingenieure. Stuttgart, BG Teubner, 1971.

8. Miller MJ, DiFiore JM, Strohl KP, Carlo WA, Martin RJ. Effect of $\mathrm{CO}_{2}$ re-breathing on pulmonary mechanics in premature infants. J Appl Physiol 1991; 70: 2582-2586.

G. Kusenbach*, H. Pott**, A. Breuer***, C. Pfannenstiel*, M. Barker*, K. Michailidis***, G. Heimann*, D. Vilozni ${ }^{+}$.

*Dept of Pediatrics of the University Hospital: Kinderklinik der RWTH Aachen; **Institute for Fluid Power Transmission and Control; ***Institute of Heat Transfer and Air Conditioning, Technical University of Aachen, Aachen, Germany. +Institute of Pulmonology, Haddasah, Jerusalem, Israel. 